\title{
The importance of rim removal in deep lateral orbital wall decompression
}

This article was published in the following Dove Press journal:

Clinical Ophthalmology

23 June 2011

Number of times this article has been viewed

\section{Hirohiko Kakizaki' \\ Yasuhiro Takahashi' \\ Akihiro Ichinose ${ }^{2}$ \\ Masayoshi Iwaki' \\ Dinesh Selva ${ }^{3}$ \\ Igal Leibovitch ${ }^{4}$}

'Department of Ophthalmology, Aichi Medical University, Nagakute, Aichi, Japan; ${ }^{2}$ Department of Plastic Surgery, Kobe University, Kobe, Hyogo, Japan; ${ }^{3}$ South Australian Institute of Ophthalmology and Discipline of Ophthalmology and Visual Sciences, University of Adelaide, South Australia, Australia; ${ }^{4}$ Division of Oculoplastic and Orbital Surgery, Department of Ophthalmology, Tel Aviv Medical Center, Tel Aviv University, Tel Aviv, Israel
Correspondence: Hirohiko Kakizaki Department of Ophthalmology, Aichi Medical University Nagakute, Aichi 480-II95, Japan Tel +8I 561623311 (ext 218I)

Fax +8I 56I 637255

Email cosme@dI.dion.ne.jp
Purpose: To evaluate the surgical outcome of deep lateral orbital decompression with or without rim removal.

Design: Retrospective case series.

Methods: Thirty-two patients (47 orbits) with Graves' orbitopathy who underwent simple deep lateral decompression or balanced lateral plus medial decompression. Of the 14 patients (24 orbits) who underwent simple deep lateral decompression, 8 (13 orbits) had temporary rim removal and in 6 ( 11 orbits) the rim was left intact. Of the 18 patients ( 23 orbits) who underwent a balanced decompression, 7 ( 9 orbits) had temporary rim removal and in 11 (14 orbits) the rim was left intact. The amount of postoperative reduction in proptosis was compared among these four groups.

Results: The average reduction in proptosis in the simple deep lateral decompression group was $5.73 \mathrm{~mm}$ (range: $4.0-8.0 \mathrm{~mm}$ ) in the rim removal group and $4.09 \mathrm{~mm}$ (range: $2.5-6.0 \mathrm{~mm}$ ) in the intact rim group $(P=0.005)$. The average reduction in proptosis in the balanced decompression group was $6.39 \mathrm{~mm}$ (range: $5.0-8.5 \mathrm{~mm}$ ) in the rim removal group and $5.07 \mathrm{~mm}$ (range: $3.0-8.0 \mathrm{~mm})$ in the intact rim group $(P=0.039)$. There was no statistically significant difference in proptosis reduction between the simple deep lateral decompression with rim removal group and the balanced decompression with an intact rim group $(P=0.220)$.

Conclusion: The rim removal approach allows a more effective decompression than the intact rim approach. Simple deep lateral decompression with rim removal approach has a similar effect to balanced decompression through an intact rim.

Keywords: deep lateral decompression, balanced decompression, rim removal, intact rim, Graves' orbitopathy, proptosis

\section{Introduction}

Deep lateral orbital wall decompression (deep lateral decompression) was first described by Leone et al in 1989 as part of balanced lateral plus medial orbital wall decompression (balanced decompression). ${ }^{1}$ The increasing popularity of the swinging eyelid approach ${ }^{2,3}$ or the trans-eyelid crease approach, ${ }^{4}$ has encouraged many surgeons to use the deep lateral decompression technique as the procedure of choice in treating disfiguring proptosis, ${ }^{5-7}$ as well as compressive optic neuropathy and congestive orbitopathy. ${ }^{8}$ This technique is thought to cause the least postoperative eye movement disturbances compared with other types of surgical decompression. ${ }^{9}$

In the original report by Leone et al, the lateral orbital rim was removed permanently and not repositioned. ${ }^{1}$ Although in their original series it was not shown to cause a significant cosmetic blemish, ${ }^{1}$ other surgeons encountered an occasional depressed 
iatrogenic deformity. ${ }^{10}$ This deformity was prevented by utilizing rim repositioning techniques with microfixation plates $^{11}$ or suture fixation. ${ }^{12}$

Paridaens et al subsequently reported the successful use of the ab interno approach. ${ }^{13}$ This technique leaves the lateral orbital rim intact, while minimally disinserting the temporalis muscle, thereby leading to less cosmetic disfigurement or chewing difficulties. This technique is also faster than the temporary rim removal approach, but it still has the disadvantages of limited visibility of the deep lateral wall while working through a relatively tight "keyhole."

The deep lateral decompression technique is mainly directed to bone removal from the greater wing of the sphenoid, which shapes a triangular prism frequently called the "trigone" of the greater wing. ${ }^{5}$ From our experience, the deep lateral area of the trigone is not completely visualized using the intact rim approach (Figure 1A), which precludes maximal removal of bone under direct visualization.

To the best of our knowledge, no studies have compared the surgical outcome of the rim removal approach with the intact rim approach in deep lateral decompression. The purpose of our study is, therefore, to evaluate the surgical outcome of these groups.

\section{Materials and methods}

This is a retrospective case series and we reviewed the clinical records of all patients (32 patients, 47 orbits) with Graves' orbitopathy seen at the Department of Ophthalmology, Aichi Medical University, Nagakute, Aichi, Japan, who underwent deep lateral decompression alone or balanced decompression for disfiguring proptosis or compressive optic neuropathy between October 2008 and February 2010. Methods complied

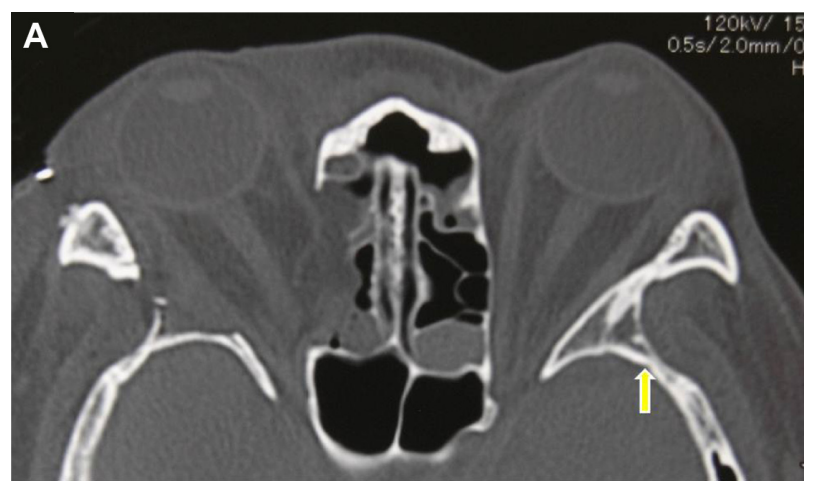

Figure IA Axial computerized tomography scan of a 39-year-old female patient with Graves' orbitopathy after right balanced decompression surgery with rim removal approach. The yellow arrow indicates the deep lateral area of the trigone of the greater wing of the sphenoid. This area becomes a dark corner under the intact rim approach. The area corresponding to the trigone in the right side was almost completely excised during surgery through the rim removal approach. with the tenets of the Declaration of Helsinki and informed consent was obtained prior to the start of this study. All the patients were in a euthyroid state and their orbitopathies were all in an inactive phase. All surgeries were performed by a single surgeon (HK), using a consistent technique. The minimum postoperative follow-up period was 6 months.

The patients' demographic data is shown in Table 1. Each of the two groups of patients who underwent decompression surgery were further subdivided into those with temporary lateral orbital rim removal and those with decompression through an intact rim. All the initial cases in this series were done with the rim intact, but the technique was changed to rim removal in the subsequent cases because we encountered a cerebrospinal fluid (CSF) leakage ${ }^{14}$ with the rim intact approach. Although the simple deep lateral decompression technique is generally selected for patients with proptosis of less than $22 \mathrm{~mm},{ }^{6}$ and balanced decompression for patients with proptosis of more than $22 \mathrm{~mm}$, we did not always follow this rule when adjusting asymmetrical proptosis or reducing the amount of proptosis to reflect the patients' preference.

Fourteen patients ( 24 orbits) were included in the simple deep lateral decompression group; 8 of them (13 orbits) underwent temporary removal of the lateral orbital rim, and in 6 patients (11 orbits) the rim was left intact. The balanced decompression group included 18 patients (23 orbits); 7 of them (9 orbits) underwent temporary removal of the lateral orbital rim and in 11 patients (14 orbits) the rim was left intact.

We examined the pre- and postoperative Hertel exophthalmometer readings and compared the amount of proptosis reduction in the group of patients who underwent deep lateral decompression alone (with or without rim removal) and in the group who underwent balanced decompression (with or without rim removal). We also compared the amount of proptosis reduction in the simple deep lateral decompression with rim removal group with the balanced decompression with rim intact group. These measurements were performed by a single examiner (HK), 6 months after the operations. Operation time was also measured in each group and comparisons were performed between the groups stated above.

Intraoperative and postoperative complications, such as CSF leakage, postoperative diplopia, and chewing difficulties related to temporal muscle disinsertion, were documented.

Statistical analysis was based on the Mann-Whitney $\mathrm{U}$ test. Statistical significance was defined as $P<0.05$. All statistical analysis was carried out using Dr SPSS for Windows (SPSS Japan Inc, Tokyo, Japan). 
Table I Patients' demographic data

\begin{tabular}{|c|c|c|c|c|}
\hline & \multicolumn{2}{|c|}{ Deep lateral decompression } & \multicolumn{2}{|c|}{ Balanced decompression } \\
\hline & $\begin{array}{l}\text { Temporary orbital } \\
\text { rim removal }\end{array}$ & Intact rim & $\begin{array}{l}\text { Temporary orbital } \\
\text { rim removal }\end{array}$ & Intact rim \\
\hline Number (patients/orbits) & $8 / 13$ & $6 / 11$ & $7 / 9$ & $11 / 14$ \\
\hline \multicolumn{5}{|l|}{ Gender (patients/orbits) } \\
\hline Male & $2 / 3$ & $3 / 5$ & $1 / 1$ & $6 / 8$ \\
\hline Female & $6 / 10$ & $3 / 6$ & $6 / 8$ & $5 / 6$ \\
\hline \multicolumn{5}{|l|}{ Side (orbits) } \\
\hline Right & 5 & 6 & 4 & 9 \\
\hline Left & 8 & 5 & 5 & 5 \\
\hline \multicolumn{5}{|l|}{ Age (years) } \\
\hline Mean & 36.9 & 36.2 & 37.0 & 38.3 \\
\hline Range & $24-50$ & $24-43$ & $20-53$ & $20-64$ \\
\hline
\end{tabular}

\section{Surgical technique}

All surgeries were performed through a swinging eyelid approach under general anesthesia aided by binocular loupes (high-resolution prismatic HRP $\times 2.5,340 \mathrm{~mm} / 13$ in; Heine, Herrsching, Germany). ${ }^{2,3}$ In the rim removal approach (Figure 1A), osteotomies were made with bone saw at a level just above the frontozygomatic suture and just above the zygomatic arch. ${ }^{6}$ Bone removal was performed using rongeurs and an ultrasound grinding apparatus (Sonopet UST-2000 ${ }^{\circledR}$, Japan Striker, Tokyo, Japan) up to the cortical bone of the posterior border of the trigone. Next, the lateral cortical bone of the trigone was also removed to allow direct visualization of the deep lateral corner of the trigone. Electrocautery, bone wax and adrenaline (1/5000) were used to obtain hemostasis. The lateral orbital rim was then repositioned with absorbable microfixation plates (SuperFixorb $\mathrm{MX}^{\circledR}$, Takiron Co, Osaka, Japan), both superiorly and inferiorly without rim advancement. In the intact rim approach (Figure 1B), the bone was removed in a similar fashion up to the cortical bone of the posterior border of

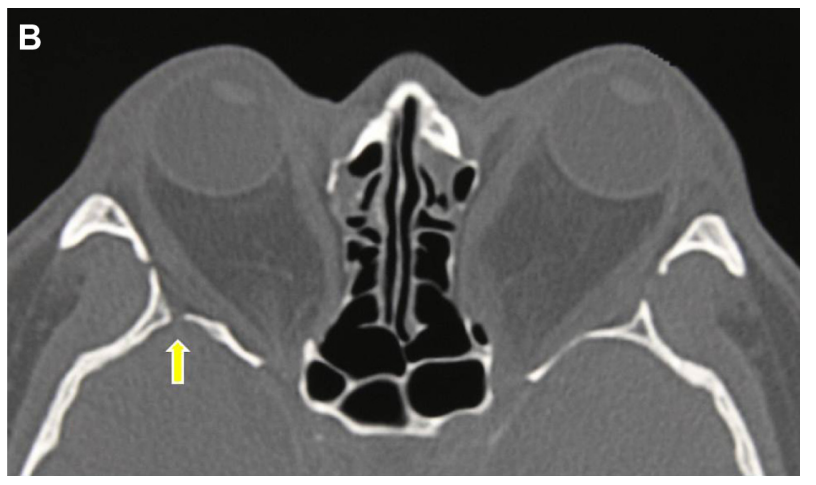

Figure IB Axial computerized tomography scan of a 34-year-old male patient with Graves' orbitopathy after bilateral balanced decompression surgery with rim intact approach. The deep lateral area of the trigone was not removed. The yellow arrow indicates the bony defect through which cerebrospinal fluid leakage occurred. the trigone. However, since direct visualization of the deep lateral area of the trigone was difficult, the bone removal was more limited. Orbital fat was removed from the inferolateral intraconal space in all patients undergoing simple deep lateral decompressions and in 16 orbits undergoing balanced decompression. Orbital fat was not removed in seven orbits undergoing balanced decompression (four in the rim removal approach and three in the intact rim approach), because the proptosis reduction was judged as sufficient without fat removal by inspection.

Medial orbital wall decompression was performed through a transcaruncular approach, as part of the balanced decompression. ${ }^{4}$ The lamina papyracea, with its periosteum, septae and mucosa of the ethmoid air cells, were removed with bone forceps starting at the level $10 \mathrm{~mm}$ posterior to the posterior lacrimal crest ${ }^{12}$ and extending to the level of the posterior ethmoidal foramen. ${ }^{15}$

\section{Results}

In the deep lateral decompression group, the average reduction in proptosis measured by the Hertel exophthalmometer was $5.73 \mathrm{~mm}$ (range: $4.0-8.0 \mathrm{~mm}$ ) in the rim removal group and $4.09 \mathrm{~mm}$ (range: $2.5-6.0 \mathrm{~mm}$ ) in the intact rim group. This difference was statistically significant $(P=0.005)$. The amount of orbital fat removed was $1.15 \mathrm{~mL}$ (range: $0.4-2.0 \mathrm{~mL}$ ) in the rim removal group and $1.50 \mathrm{~mL}$ (range: 1.0-2.0 mL) in the intact rim group. This difference was not statistically significant $(P=0.119)$ and almost same amount of fat was removed in both groups. Based on these results, a larger amount of bone was removed in the rim removal group than in the intact rim group.

In the balanced decompression group, the average reduction in proptosis measured by the Hertel exophthalmometer was $6.39 \mathrm{~mm}$ (range: $5.0-8.5 \mathrm{~mm}$ ) in the rim removal group 
and $5.07 \mathrm{~mm}$ (range: $3.0-8.0 \mathrm{~mm}$ ) in the intact rim group. This difference was statistically significant $(P=0.039)$. The amount of orbital fat removed was $0.49 \mathrm{~mL}$ (range: $0-1.3 \mathrm{~mL}$ ) in the rim removal group and $1.18 \mathrm{~mL}$ (range: $0-2.8 \mathrm{~mL}$ ) in the intact rim group. This difference was not statistically significant $(P=0.062)$ and almost same amount of fat was removed in both groups. Based on these results, a larger amount of bone was removed in the rim removal group than in the intact rim group.

There was no significant difference in the amount of proptosis reduction between the simple deep lateral decompression with rim removal group and the balanced decompression with an intact rim group $(P=0.220)$. Since there was no significant difference in the amount of orbital fat removal in these two groups $(P=0.943)$, this factor should not have an effect on the comparison between the two decompression techniques.

The average surgical time for simple deep lateral decompression with rim removal was 159.2 minutes (range: 113-204 minutes) whereas the duration of this surgery with an intact rim was 128.2 minutes (range: 116-154 minutes) $(P=0.002)$. The average surgical time of the balanced decompression with rim removal was 222.7 minutes (range: 177-262 minutes), whereas the duration of this surgery with an intact rim was 189.4 minutes (range: 154-220 minutes) $(P=0.017)$. The surgical time for the simple deep lateral decompression with rim removal approach was significantly shorter than the balanced decompression through an intact rim approach $(P=0.003)$.

One case of CSF leakage was encountered in the deep lateral corner of the trigone during the intact rim approach in a balanced decompression (Figure 1B). The bony defect was patched with bone wax and the CSF leakage stopped. Intravenous antibiotic (1 $\mathrm{g}$ of ceftriaxone sodium) was administered twice a day for one week after the operation with no occurrence of any symptoms of meningitis. All the patients who had rim removal in both simple deep lateral decompression and in balanced decompression had some degree of chewing difficulties, without masticatory oscillopsia, for a limited period of no more than 6 months. Although all the patients in both groups demonstrated various degrees of eye movement worsening in the early postoperative period, it recovered to a normal level in the postoperative 6 months.

\section{Discussion}

We showed that removing the orbital rim enables better visualization of the deep lateral corner of the trigone and results in a more effective reduction in proptosis, both in simple deep lateral decompression and in balanced decompression. Since the amount of removed orbital fat was similar in both groups, this factor had no confounding effect on the comparison of bone-related reduction in proptosis.

The simple deep lateral decompression with rim removal technique had a similar effect on proptosis reduction as balanced decompression with an intact rim but with a shorter surgical time. Since we removed a similar amount of orbital fat in these two groups, this factor should have no significant effect on the comparison. It is believed that when a larger number of walls are removed during decompression, the risk of postoperative eye movement disturbances or worsening of preoperative strabismus is higher. ${ }^{9}$ Accordingly, when a twowalls (balanced) decompression is recommended according to the guidelines of the graded decompression algorithm, ${ }^{6}$ it may be preferable to choose simple deep lateral decompression with rim removal since only one wall is removed. However, since the volume of the trigone may vary among patients, ${ }^{16}$ the final choice of the decompression technique should take this factor into account.

The deep lateral decompression approach in our study, in cases with or without rim removal, achieved a considerable degree of proptosis reduction even in comparison with other studies $^{6,13}$ and despite removing only a small amount of orbital fat. This could be explained by a maximal amount of bone removal, up to the cortical bone of the posterior border of the trigone.

The one case of CSF leakage that was encountered in our series was in a patient undergoing decompression through an intact rim approach. This was the reason we changed the technique to the rim removal approach. Removing the orbital rim enables a safe and effective operation, especially in patients with a large outer extension of the trigone. Although CSF leakage may still occur when the rim is removed, ${ }^{12}$ the risk can be reduced by using magnifying loupes, which allow definite visualization of the posterior border of the trigone.

Postoperative chewing difficulties and a longer surgical time are the main disadvantages of the rim removal approach. In these respects, rim removal can be avoided in patients with milder proptosis. In all other cases, however, the longer surgical time is justified to allow a safer operation with a larger and more convenient surgical field. The chewing difficulties are usually temporary and resolve within 6 months.

In conclusion, removal of the orbital rim in deep lateral wall decompression enabled a more effective reduction in proptosis compared to the rim intact group. Simple deep lateral decompression with rim removal has a similar 
effect to balanced decompression through an intact rim. A longer surgical time and temporary postoperative chewing difficulties are the main drawbacks of the rim removal approach.

\section{Disclosure}

The authors report no conflicts of interest in this work.

\section{References}

1. Leone CR, Piest KL, Newman RJ. Medial and lateral wall decompression for thyroid ophthalmopathy. Am J Ophthalmol. 1989;108(2):160-166.

2. McCord CD Jr. Orbital decompression for Graves' disease: exposure through lateral canthal and inferior fornix incision. Ophthalmology. $1981 ; 88(6) ; 533-541$.

3. Rootman J, Stewart B, Goldberg RA. Decompression for thyroid orbitopathy. In: Orbital Surgery: A Conceptual Approach. Philadelphia, PA: Lippincott-Raven; 1995:353-384.

4. Shorr N, Baylis HI, Goldberg RA, Perry JD. Transcaruncular approach to the medial orbit and orbital apex. Ophthalmology. 2000;107(8): 1459-1463.

5. Goldberg RA, Kim AJ, Kerivan KM. The lacrimal keyhole, orbital door jamb, and basin of the inferior orbital fissure: three areas of deep bone in the lateral orbit. Arch Ophthalmol. 1998;116(12):1618-1624.

6. Kikkawa DO, Pornpanich K, Cruz RC Jr, Levi L, Granet DB. Graded orbital decompression based on severity of proptosis. Ophthalmology. 2002;109(7):1219-1224.
7. Chang EL, Piva AP. Temporal fossa orbital decompression for treatment of disfiguring thyroid-related orbitopathy. Ophthalmology. 2008;115(9): $1613-1619$

8. Goldberg RA. The evolving paradigm of orbital decompression surgery Arch Ophthalmol. 1998;116(1):95-96.

9. Goldberg RA, Perry JD, Hortaleza V, Tong JT. Strabismus after balanced medial plus lateral wall versus lateral wall only orbital decompression for dysthyroid orbitopathy. Ophthal Plast Reconstr Surg. 2000;16(4):271-277.

10. Baldeschi L. Small versus coronal incision orbital decompression in Graves' orbitopathy. Orbit. 2009;28(4):231-236.

11. Goldberg RA, Hwang MM, Garbutt MV, Shorr N. Orbital decompression for non-Graves' orbitopathy: a consideration of extended indications for decompression. Ophthal Plast Reconstr Surg. 1995;11(4):245-252.

12. Bailey KL, Tower RN, Dailey RA. Customized, single-incision, three-wall orbital decompression. Ophthal Plast Reconstr Surg. 2005; 21(1):1-9.

13. Paridaens DA, Verhoeff K, Bouwens D, van Den Bosch WA. Transconjunctival orbital decompression in Graves' ophthalmopathy: lateral wall approach ab interno. Br J Ophthalmol. 2000;84(7):775-781.

14. Limawararut V, Valenzuela AA, Sullivan TJ, et al. Cerebrospinal fluid leaks in orbital and lacrimal surgery. Surv Ophthalmol. 2008;53(3): 274-284.

15. Liao SL, Chang TC, Lin LL. Transcaruncular orbital decompression: an alternate procedure for Graves ophthalmopathy with compressive optic neuropathy. Am J Ophthalmol. 2006;141(5):810-818.

16. Kakizaki H, Nakano T, Asamoto K, Iwaki M. Posterior border of the deep lateral orbital wall: appearance, width, and distance from the orbital rim. Ophthal Plast Reconstr Surg. 2008;24(4):262-265.
Clinical Ophthalmology

\section{Publish your work in this journal}

Clinical Ophthalmology is an international, peer-reviewed journal covering all subspecialties within ophthalmology. Key topics include: Optometry; Visual science; Pharmacology and drug therapy in eye diseases; Basic Sciences; Primary and Secondary eye care; Patien Safety and Quality of Care Improvements. This journal is indexed on

Submit your manuscript here: http://www.dovepress.com/clinical-ophthalmology-journal

\section{Dovepress}

PubMed Central and CAS, and is the official journal of The Society of Clinical Ophthalmology (SCO). The manuscript management system is completely online and includes a very quick and fair peer-review system, which is all easy to use. Visit http://www.dovepress.com/ testimonials.php to read real quotes from published authors. 